\title{
Os sujeitos e suas representações: a educação a distância e os dizeres dos alunos acerca da modalidade
}

\author{
Isabel Cristiane Jerônimo \\ Universidade Estadual de Londrina (UEL), Londrina, Paraná, Brasil \\ cristianejeronimo@terra.com.br \\ http://orcid.org/0000-0001-8887-2943
}

DOI: http://dx.doi.org/10.21165/el.v47i3.1945

\begin{abstract}
Resumo
O objetivo deste trabalho é analisar os sistemas de representação que emergem do discurso de sujeitos que concluíram (ou estão cursando) o ensino a distância, levando-se em conta: 1) a imagem que esses sujeitos constroem a respeito da modalidade; 2 ) a imagem que elaboram a respeito do perfil de aluno que frequenta esse tipo de ensino. No início do século XXI, com o fortalecimento das Novas Tecnologias de Informação e Comunicação incorporadas ao contexto educacional, ainda havia muita desconfiança do mercado de trabalho e das instituições de ensino presenciais acerca do êxito profissional desses alunos. Entretanto, com os resultados positivos da inserção desses profissionais em setores especializados da sociedade, a modalidade alcançou novo status nas práticas educacionais. Dessa forma, parte-se da hipótese de que a construção das representações desses sujeitos no contexto sócio-histórico-educacional contemporâneo é positiva. Pressupostos da Análise de Discurso francesa e dos Estudos Culturais fundamentarão a análise.
\end{abstract}

Palavras-chave: aluno a distância; imaginário sociodiscursivo; representação; discurso.

The subjects and their representations: distance education and students' comments about the modality

\begin{abstract}
The objective of this work is to analyze the representation systems that emerge from the discourse of subjects who concluded (or are studying) distance learning, taking into account: 1) the image these subjects construct about the modality; 2) the image they elaborate regarding the student profile that attends this type of teaching. At the beginning of the XXI century, with the strengthening of the new information and communication technologies incorporated into the educational context, there was still a great deal of distrust from the labor market and face-toface teaching institutions about the professional success of these students. However, with the positive results of the insertion of these professionals in specialized sectors of society, the modality reached new status in educational practices. Thus, the hypothesis is that the construction of the representations of these subjects in the contemporary socio-historicaleducational context is positive. Assumptions of French Discourse Analysis and Cultural Studies will support the analysis.
\end{abstract}

Keywords: distance education student; socio-discursive imaginary; representation; discourse

\section{Introdução}

O foco deste artigo é a busca pelo modo como ocorre a construção do imaginário sociodiscursivo de sujeitos que concluíram (ou ainda estão cursando) a educação a distância na posição de alunos. Temos o intuito de investigar, via discurso, a imagem 
construída por eles sobre o que é ser um aluno nesse contexto, bem como as representações relacionadas a essa modalidade. Além disso, tencionamos analisar, nessa formação discursiva, os aspectos ideológicos que perpassam os dizeres desses sujeitos que partilham da atividade humana de estudar a distância.

Compreender como se constrói esse tipo de discurso é relevante para que possamos perceber a construção de identidades envolvidas na relação ensinoaprendizagem na contemporaneidade. A partir da década de 1990, as Tecnologias digitais de informação e comunicação na Educação a distância foram incorporadas às Instituições de Ensino Superior (IES), possibilitando o acesso ao conhecimento via internet. Inicialmente vista com muita desconfiança em relação à qualidade do ensino, seja pelo mercado de trabalho, por professores, pelas instituições de ensino presenciais ou pela própria sociedade em geral, hoje essa modalidade parece estar fortalecendo-se. Segundo a Associação Brasileira de Educação a Distância (ABED), os dados do Censo da Educação Superior, divulgados em 2013, mostram que a EAD no Brasil encerrou 2012 com 1,2 milhão de alunos matriculados.

Tamanho interesse e participação dos que se sentem seduzidos por esse tipo de ensino, como nos mostram os dados, tende a fazer com que o imaginário social sobre a modalidade vá transformando-se, ainda que lentamente. Assim, partimos da hipótese de que a construção das representações desses sujeitos no contexto sócio-históricoeducacional contemporâneo pode apresentar aspectos positivos, em contraposição aos estereótipos negativos vinculados às representações passadas. Tais representações foram motivadas pela comparação do aluno do meio virtual com o aluno do ensino presencial, este último visto como mais bem preparado pela presença constante do professor; e pela hegemonia das instituições presenciais, eleitas historicamente como condição sine qua non para que a qualidade no aprendizado fosse alcançada.

A fim de discutirmos essas questões, o artigo foi dividido em quatro seções. A primeira trata da fundamentação teórica referente à Educação a distância; a segunda aborda reflexões sobre o campo da Análise do discurso francesa; a terceira apresenta alguns conceitos relativos às representações sociais e ao imaginário sociodiscursivo; na quarta seção trataremos de questões metodológicas referentes ao corpus e procederemos à análise dos dados. Em seguida, apresentaremos as considerações finais.

\section{Educação a distância: breve contextualização}

Em busca do funcionamento discursivo dos dizeres de alunos e de egressos de cursos a distância, algumas considerações acerca dessa modalidade fazem-se necessárias, a fim de caracterizá-la.

Quando se pensa em educação formal, o que vêm à mente de grande parte das pessoas são locais fisicamente delimitados que atuam como principal espaço para se desenvolver essa atividade. $\mathrm{O}$ binômio ensinar-aprender esteve vinculado, por muito tempo, às instituições de ensino "físicas", estáveis no tempo e no espaço, e o conhecimento valorizado e legitimado socialmente circulava dentro dessas instituições, para as quais os indivíduos se deslocavam com o intuito de adquirir conhecimento e, assim, firmarem-se no mercado de trabalho.

Entretanto, desde o final do século XX e, principalmente, no início do século $\mathrm{XXI}$, surgiu uma outra possibilidade de os sujeitos se relacionarem com os saberes: as 
tecnologias de informação e comunicação. Dessa forma, não são mais os alunos que se locomovem em busca dos conteúdos, mas estes estão à disposição dos que se interessam em acessá-los virtualmente. Quando e onde fazer isso já não são mais questões limitadoras para os que querem participar do rol de graduados, pós-graduados ou dos que decidem incrementar seus conhecimentos em cursos rápidos, por meio da Educação a Distância (EaD).

As primeiras experiências registradas em EaD em nosso país datam do século XX, sempre vinculadas à formação profissional. Nas décadas de 1970 e 1980, cursos supletivos a distância eram oferecidos por instituições particulares ou não governamentais, por meio de aulas via satélite, complementadas por materiais impressos. O uso das Novas Tecnologias de Informação e Comunicação (NTIC's) foi incorporado pelas Instituições de Ensino Superior somente a partir da década de 1990 (BELLONI, 2002, p. 90).

Há vários olhares quando se procura definir essa modalidade de ensino, dependendo do foco. De acordo com Belloni (2002, p. 123), a EaD pode ser definida como "[...] parte de um processo de inovação educacional mais amplo que é a integração das novas tecnologias de informação e comunicação nos processos educacionais." . Ou ainda, de acordo com Moran (2002, p. 1) ${ }^{1}$,"Educação a distância é o processo de ensino-aprendizagem, mediado por tecnologias, onde professores e alunos estão separados espacial e/ou temporalmente.”. Pode haver ou não encontros presenciais nessa modalidade.

Em relação ao público-alvo, Moran (2002) afirma que a EaD é mais adequada a adultos, principalmente aos que possuem experiência em estudo individual e pesquisa, como ocorre na graduação e na pós-graduação. Os responsáveis por elaborar os programas dos cursos a distância precisam levar em conta as motivações do adulto que escolhe essa modalidade, já que se trata de alguém com muitas preocupações em relação ao trabalho, à família e à vida social. (MOORE; KEARSLEY, 2007, p. 197). Ainda levando em conta o perfil do aluno, Preti (1996) diz que a busca por esse tipo de educação ocorre, principalmente, por aqueles que não puderam participar da modalidade presencial, seja pelo local onde residem, seja pela condição social, ou pela ausência de oferta de determinados níveis ou cursos na região onde moram. O autor acrescenta, ainda, questões familiares e econômicas como pontos relevantes para a escolha da modalidade.

Belloni (2008) afirma que as habilidades essenciais a um aluno dessa modalidade são autodisciplina, automotivação, responsabilidade e capacidade de gerenciar o seu tempo. A pré-disposição individual para aprender a aprender também é fundamental em tempos de ensino mediado por computador, em que há um "isolamento" físico maior do aluno em relação aos colegas e aos professores, se comparado ao ensino presencial. Em consonância com a autora, Preti (1996, p. 27) afirma que:

A EaD coloca-se como um conjunto de métodos, técnicas e recursos postos à disposição de populações estudantis dotadas de um mínimo de maturidade e de motivação suficiente para que, em regime de autoaprendizagem, possam adquirir conhecimentos

\footnotetext{
${ }^{1}$ Moran (2002) prefere "educação a distância" a "ensino a distância" por ser uma expressão mais abrangente e não colocar em foco o papel do professor. Entretanto, julga as duas expressões como não sendo plenamente adequadas.
} 
ou qualificações a qualquer nível. A EaD cobre distintas formas de ensinoaprendizagem em todos os níveis que não tenham a contínua supervisão imediata de professores presentes mas que, no entanto, se beneficiam do planejamento, guia, acompanhamento e avaliação de uma organização educacional.

Além do perfil de aluno pretendido pela $\mathrm{EaD}$, é preciso levar em conta o aspecto social e econômico mais amplo em que se insere a modalidade. Esse tipo de aprendizagem incorpora-se ao modo de produção capitalista vigente, ou seja, de diversas formas "o campo educacional se coloca a serviço do capital" (MINTO, 2009, p. 9). Portanto, os cursos oferecidos pelas universidades ou por outros centros de educação on-line buscam seguir a tendência do mercado e as exigências desta sociedade contemporânea, a qual cobra intensamente do sujeito o desenvolvimento da capacidade de lidar com realidades mais complexas com competência e rapidez, um trabalhador "multiqualificado e multicompetente, capaz de gerir situações de grupo, de se adaptar a situações novas, sempre pronto a aprender. Em suma, um trabalhador mais informado e mais autônomo" (BELLONI, 2009, p. 39). De um ponto de vista mais crítico em relação ao contexto econômico em que se insere a EaD, Minto $(2009$, p. 3$)$ afirma que:

A implantação das práticas de EaD na educação superior erguem-se sobre a mesma base da reestruturação capitalista, que pressupõe: maior concentração do capital, precarização das relações de trabalho, restrição de direitos à classe trabalhadora, ampliação das taxas de lucro, ampliação progressiva do tempo de exploração da força de trabalho e crescente produtividade etc.

Dessa forma, não podemos perder de vista, em uma análise discursiva, que junto à noção de democratização do conhecimento, tão apregoada por estudiosos da área de $\mathrm{EaD}$, e à inegável expansão dessa modalidade de ensino, devem ser estabelecidas relações com o âmbito econômico, as quais não devem ser negligenciadas, sob pena de se proceder a uma leitura parcial.

Passando do nível econômico para o estrutural, não há como essa nova forma de aprender incorporar-se à vida do graduando sem que alguém o oriente. Em outras palavras, ao aluno não será possível desenvolver-se neste novo contexto educacional sem contar com o auxílio dos outros componentes humanos que constituem o processo: professores especialistas, tutores e os responsáveis pela elaboração do material pedagógico. É preciso encaminhá-lo para que se torne um sujeito autônomo na EaD, a fim de que compreenda o funcionamento do sistema, conseguindo organizar-se em seus estudos.

Apesar das vantagens apontadas por estudiosos da área, como "abertura, flexibilidade, adaptação, eficácia, formação permanente e economia" (PRETTI, 1996, p. 26-27), isso não significa que esse não seja um espaço para questionamentos e dúvidas numa perspectiva social, já que ainda existe uma certa resistência quando o assunto é a EaD em países do terceiro mundo, os quais não são vistos como estimuladores de uma cultura do autodidatismo, de acordo com o mesmo autor.

Poder-se-ia dizer que esse é um pensamento da "década de noventa" e que hoje as mentes já não raciocinam mais dessa forma, dados os tempos tecnológicos em que vivemos. Entretanto, Fontana (2013, p. 14), quase uma década depois, afirma que "embora a EaD seja uma vetusta senhora", ainda é vista entre nós como novidade. O autor levanta como hipótese, para a resistência desse pensamento anacrônico, o uso 
recente que as pessoas fazem da internet, meio vital para a comunicação a distância. Afirma, ainda, que há vários tipos de ideias preconcebidas em relação à EaD, destacando o que poderia ser chamado de "falta de qualidade" e "uma educação de segunda linha". Apesar disso, a modalidade continua expandindo-se.

Concluído esse panorama acerca da $\mathrm{EaD}$, serão abordados alguns conceitos relativos à Análise do discurso francesa e aos Estudos culturais, os quais formam a fundamentação teórica que embasa a análise do corpus.

\section{0 discurso e suas implicações}

O discurso, como nos diz Pêcheux (1995), é o lugar de entrelaçamento da língua com a história. A produção de linguagens concretiza-se no discurso e produzi-lo é gerar efeitos de sentido que marcam as posições ideológicas, sociais e culturais dos sujeitos em uma sociedade. $\mathrm{O}$ discurso é exterior à língua, embora ela lhe seja necessária para a sua concretização. Quando se tem o discurso como objeto de análise, a condição sine qua non é levarem-se em conta as determinações históricas para a observação de como se dá a construção dos sentidos.

Ainda segundo Pêcheux (2012), nenhum discurso é homogêneo, unívoco, independente da memória discursiva e dos trajetos sociais de que provém. A propósito, o conceito de memória, segundo Courtine (2009, p. 105), não se relaciona à memorização psicológica, mas diz respeito "à existência histórica do enunciado no interior de práticas discursivas regradas por aparelhos ideológicos.”. Da memória discursiva fazem parte os discursos que, além de sua formulação, são ditos, permanecem ditos e ainda estão por dizer. Ou seja, esse conjunto de sequências que preexistem a um enunciado permitem a retomada, a repetição, a refutação e também o esquecimento dos elementos de saber que são enunciados (COURTINE, 2009, p. 106). Para Achard (2007, p. 16-17) "[...] a memória suposta pelo discurso é sempre reconstruída na enunciação" e "[...] a memória não restitui frases escutadas no passado, mas julgamentos de verossimilhança sobre o que é reconstituído pelas operações de paráfrase". Dessa forma, a operação de retomada dos dizeres situa-se no nível da historicidade.

Retomando a ideia de ausência de homogeneidade anteriormente citada, para Pêcheux um discurso ocorre sempre em relação a outros, com os quais estabelece concordâncias ou dissonâncias. Por isso, o conceito de interdiscurso é fundamental à Análise do Discurso (AD) já que, por meio dele, produz-se sentido num dado momento histórico, ou seja, os sentidos só podem ser determinados historicamente:

Não se trata de pretender aqui que todo discurso seria como um aerólito miraculoso, independente das redes de memória e dos trajetos sociais nos quais ele irrompe, mas de sublinhar que, só por sua existência, todo discurso marca a possibilidade de uma desestruturação-reestruturação dessas redes e trajetos: todo discurso é o índice potencial de uma agitação nas filiações sócio-históricas de identificação [...] (PÊCHEUX, 2012, p. 56).

O discurso é o lugar teórico em que as polêmicas sociais são travadas por meio das palavras enunciadas pelos sujeitos. Para Fernandes (2008), entender o sujeito discursivo é compreender as vozes sociais que ecoam em sua voz. Por não ser 
homogêneo, seu discurso é atravessado por outros que estão em oposição, negando-se e contradizendo-se. "No interior dos discursos, o sujeito assume diferentes posições, portanto a sua identidade nunca será a mesma em diferentes momentos e lugares em que se encontre" (FERNANDES, 2008, p. 33). Esta relação que envolve sujeito, linguagem e história impele o analista a tratar do conceito de formação discursiva.

O termo Formação discursiva, cunhado por Michel Foucault em sua obra Arqueologia do saber (1969) e apropriado por Pêcheux num processo de releitura, define-se da seguinte forma:

A análise de uma FD estudaria formas de repartição [...], descreveria sistemas de dispersão. Na possibilidade de descrever entre um certo número de enunciados, um semelhante sistema de dispersão, ou de definir entre os objetos tipos de enunciação, conceitos, escolhas temáticas, uma regularidade [...] dir-se-á [...] que se trata de uma FD. Chamar-se-ão regras de formação as condições às quais são submetidos os elementos desta repartição. As regras de formação são as condições de existência [...] em uma dada distribuição discursiva (FOUCAULT, 1969, apud COURTINE, 2009, p. $82-83)$.

Na visão de Foucault, uma FD apresenta um caráter contraditório constitutivo, já que é formada, ao mesmo tempo, por unidade e diversidade. A heterogeneidade fica por conta da multiplicidade de discursos que constituem uma mesma formação discursiva, denominada por Foucault como dispersão. Um mesmo enunciado pode aparecer em formações discursivas diferentes, gerando sentidos diferentes, dependendo da posição sócio-histórica de quem enuncia. Da mesma forma, toda formação discursiva dialoga com outras, replicando-a, criticando-a, contestando-a ou fazendo coro a ela. Já a regularidade discursiva fica por conta dos enunciados e suas regras de formação (tipos de enunciação, conceitos, escolhas temáticas).

Para tratar dos dizeres daqueles que tomaram a posição de alunos do EaD é fundamental levar em consideração que o enunciado é sempre assumido por um sujeito, constituído, ele mesmo, por discursos historicamente produzidos e modificados. $\mathrm{O}$ sujeito é um dos pilares daquilo que se denomina condições de produção do discurso, conjunto de elementos que constitui um processo discursivo. "Toda fala procede de um enunciador encarnado; mesmo quando escrito, um texto é sustentado por uma voz: a de um sujeito situado para além do texto" (MAINGUENEAU, 2001, p. 95). Em AD, o sujeito caracteriza-se por ser marcado pela instabilidade, já que está em constante construção de sua identidade, pela não unificação psicológica (dividido entre consciente e inconsciente), e por não se constituir como a origem do seu dizer.

Além disso, de acordo com Pêcheux (1995), o sujeito é afetado, na produção de seu discurso, por esquecimentos de ordem ideológica e enunciativa, ou seja, tem a ilusão de ser a origem do que diz, de modo inconsciente, e de maneira pré-consciente ou consciente, pensa ter pleno domínio das estratégias discursivas que envolvem o seu dizer.

Levando em conta a questão dos aspectos ideológicos relacionados às formações discursivas, Pêcheux (1995, p. 161), num diálogo com a perspectiva althusseriana sobre ideologia, afirma que "os indivíduos são "interpelados" em sujeitos de seu discurso pelas formações discursivas que representam "na linguagem" as formações ideológicas que lhes são correspondentes". Na visão de Pêcheux e Fuchs (1990, p. 166), a formação 
ideológica diz respeito a um "conjunto complexo de atividades e de representações que não são nem individuais nem universais, mas se relacionam mais ou menos diretamente às posições de classes em conflito umas com as outras". Contribuindo com a discussão sobre o conceito, Orlandi (1998 p. 56) afirma que a ideologia é "a interpretação de sentidos determinada pela relação da linguagem com a história em seus mecanismos imaginários. Não é ocultação, mas função necessária entre linguagem e mundo".

Perceber como se constituem os sujeitos desta pesquisa em relação ao discurso sobre o que vem a ser um aluno a distância é um dos pontos de reflexão desse trabalho. Para isso, é necessário trazermos para a discussão teórica as noções de representação social e de imaginário sociodiscursivo.

\section{Representação social e imaginário sociodiscursivo}

Só é possível compreender-se os meandros do discurso por meio de uma perspectiva social. De acordo com Moita Lopes (2002), a construção dos significados se dá pelo próprio envolvimento do interlocutor na ação discursiva e pelo modo como esse interlocutor envolve outros em seu discurso, o qual se engendra em condições sóciohistóricas e institucionais específicas. Por isso, o autor afirma que alteridade e contexto são fundamentais para que os significados construídos sejam compreendidos. "As pessoas se tornam conscientes de quem são construindo suas identidades sociais ao agir no mundo por intermédio da linguagem.” (MOITA LOPES, 2002, p. 30).

Como os alunos que frequentaram/frequentam a modalidade a distância concebem as relações educacionais no contexto contemporâneo? E como concebem a si mesmos enquanto participantes dessa formação discursiva na qual, para se definirem, necessariamente devem levar em consideração o outro, sem o qual as práticas discursivas não se concretizam? Como se significam em seu discurso, levando-se em conta essa posição sujeito, memória e ideologia? Para que essas questões sejam respondidas é preciso tratar do conceito de representação.

De acordo com Woodward (2014, p. 18), “a representação inclui as práticas de significação e os sistemas simbólicos por meio dos quais os significados são produzidos, posicionando-nos como sujeitos. É por meio dos significados produzidos pelas representações que damos sentido a nossas experiências e àquilo que somos.". Ainda de acordo com a autora, as representações são construídas culturalmente. As identidades geradas por essas representações são marcadas pela diferença e estão sempre em construção (WOODWARD, 2014). Jodelet (2001, p. 22) afirma que as representações sociais são "uma forma de conhecimento socialmente elaborada e partilhada; tem um objetivo prático e concorre para a construção de uma realidade comum a um conjunto social".

Contribuindo com essa discussão, Charaudeau (2013) afirma que tais representações são modos de ver e valorar o mundo por meio de discursos que carregam consigo saberes, ou seja, formas de dizer que auxiliam na construção de sistemas de pensamento e estruturam as representações sociais. O autor os divide em dois grupos: os saberes de conhecimento e os saberes de crença. Os primeiros constroem uma representação da realidade pautada na cientificidade e seus conceitos são empregados pela coletividade; já os saberes de crença discursivizam um olhar valorativo sobre o mundo. 
Fundamental para este trabalho é a noção de imaginário sociodiscursivo, cunhada pelo autor a partir da reflexão acerca desses saberes e dos sistemas de pensamento a que eles dão origem:

À medida que esses saberes, enquanto representações sociais, constroem o real como universo de significação, segundo o princípio de coerência, falaremos de "imaginários". E tendo em vista que estes são identificados por enunciados linguageiros produzidos de diferentes formas, mas semanticamente reagrupáveis, nós os chamaremos de "imaginários discursivos". Enfim, considerando que circulam no interior de um grupo social, instituindo-se em normas de referência por seus membros, falaremos de "imaginários sociodiscursivos". (CHARAUDEAU, 2013, p. 203).

Ainda de acordo com o autor (CHARAUDEAU, 2013), a realidade por si só não pode ser apreendida. É preciso que o sujeito a interprete, por meio de suas representações e de sua relação com o outro, para que ela ganhe sentido. Os imaginários surgem da relação dos sujeitos entre si e deles com o mundo, relação que faz emergir percepções e valorações da realidade por meio dos discursos. Quanto ao aspecto consciente ou não consciente que envolve a construção de imaginários, alguns são racionalizados pelos discursos que circulam em instituições como escola, instituições religiosas, poder judiciário, outros circulam de forma inconsciente e naturalizada nos juízos de valor implícitos nos enunciados. A consciência pode emergir nesse tipo de enunciado quando há confronto de posições na sociedade. Há ainda os imaginários que se constituem no chamado inconsciente coletivo "pois todas essas implicações complexas são tecidas ao longo da história, constituindo uma memória coletiva de longo termo que na prática é identificável apenas por uma abordagem histórica e antropológica" (CHARAUDEAU, 2013, p. 205).

Os imaginários sociodiscursivos implicam interdiscursividade, expõem o que pensam de suas atividades sociais determinados grupos. Analisar como se constrói a relação entre imaginário sociodiscursivo, história e ideologia nos dizeres de alunos a distância é um dos propósitos desse trabalho.

\section{Constituição do corpus e análise}

\subsection{O corpus}

O material para análise compõe-se de 15 entrevistas, 14 delas com alunos que já participaram da modalidade a distância, em diversos níveis (cursos rápidos para atualização profissional, graduação e pós-graduação em diversas áreas) e uma com um informante que, atualmente, cursa uma graduação a distância. $O$ critério para ser participante da pesquisa era ter passado pela modalidade em cursos que tivessem uma duração de, pelo menos, dois meses, não importando o nível cursado, já que a pergunta de pesquisa apresenta um caráter bastante abrangente e por isso também nos interessam os dizeres de participantes de cursos a distância com pouca duração.

A faixa etária dos informantes varia de 19 a 60 anos. Com exceção de um informante, todos os outros são alunos ou funcionários da Universidade Estadual de Londrina. Do total de entrevistados, nove cursaram graduação a distância; dois, pós- 
graduação a distância e quatro fizeram cursos de aprimoramento ou capacitação para progredir em seu trabalho ou somente para crescimento pessoal.

A coleta de dados foi feita por meio de entrevistas semiestruturadas, com dez perguntas feitas face a face, gravadas em áudio e, posteriormente, transcritas. O período em que esses informantes foram cursistas a distância vai de 2008 a 2014. Serão discutidos apenas recortes discursivos, selecionados a partir de regularidades, ou seja, de dizeres que se repetiam a partir da questão feita aos informantes, o que possibilita a percepção do imaginário sociodiscursivo. Os sujeitos foram identificados pela letra $\mathrm{S}$, seguida do número da entrevista.

\subsection{Análise}

Enunciando da posição de quem já participou ou participa como discente da $\mathrm{EaD}$, os sujeitos da pesquisa constroem suas representações acerca do que é ser um aluno dessa modalidade a partir de sua vivência sócio-histórica, entrelaçando-a à materialidade do dizer. Da formulação do dito, emergem aspectos ideológicos que remetem ao interdiscurso que atravessa intimamente a formação discursiva da educação on-line: o discurso da educação presencial, o qual, por oposição, constitui os dizeres sobre a $\mathrm{EaD}$.

Quando questionados sobre se haveria ou não diferenças entre ser um aluno presencial ou ser um aluno a distância, os sujeitos, que já possuíam referências advindas de ambas formações discursivas, posicionaram-se afirmativamente em relação à questão, o que pode ser observado nas regularidades apontadas a seguir.

Os sujeitos entrevistados consideram que ser um aluno da modalidade a distância é fazer parte de um grupo que deve esforçar-se muito mais para alcançar o aprendizado do que o aluno que faz parte da modalidade presencial. Este é representado como participante de uma formação discursiva que parece ser vista pelos sujeitos entrevistados como sendo paternalista ${ }^{2}$ :

(01) S12- "[...] o professor fica muito em cima dele"; S15- O aluno presencial, o professor está ali com ele, tira as dúvidas na hora; S16- "não é aquele negócio do professor ali em cima de você".

Ampliando esse mesmo raciocínio, observa-se que o fato de haver uma espera do aluno pela resposta às suas questões, em sistemas assíncronos, faz com que o ensino presencial seja representado como uma fonte de respostas rápidas ofertadas pelo professor, conseguidas, portanto, sem a necessidade de esforço de pesquisa por parte do aluno:

(02) S1 - "não é a mesma coisa de você ter um retorno imediato do professor, assim, quando você tá cara a cara com ele."; S10- "É que no presencial o professor está toda hora ali para tirar dúvida."; S13- "Pelo menos o que eu percebo é que o aluno presencial, ele tem mais oportunidades, porque ele está junto com o professor $[\ldots]$ ".

Outro efeito de sentido presente nos dizeres desses sujeitos é a existência de uma possível "flexibilidade" dos professores de cursos presenciais no modo como conduzem

\footnotetext{
${ }^{2}$ De acordo com o dicionário Houaiss (2004), uma das acepções da palavra paternalismo é a "prática protetora em relações de trabalho, política, etc.”.
} 
as aulas e a avaliação nesta modalidade. A atitude transigente dos docentes é reiterada pela presença de benesses, as quais não têm espaço na $\mathrm{EaD}$, de acordo com os dizeres dos sujeitos:

(03) S3-“[...] se você não fizer, ele te bloqueia e não tem mais como você entrar."; S16"Na faculdade presencial às vezes o professor fala "vou dar trabalho, não vou dar prova", então às vezes pode facilitar nessa parte."; $\mathrm{S} 14$-"No EaD é diferente, lá não tem choro, eu tenho que ter regularidade de acesso ao ambiente."

A utilização da expressão "lá não tem choro" materializa um discurso atravessado por uma memória que recupera o que Pêcheux (2014, p. 154) chama de efeito de pré-construído por meio do interdiscurso, neste caso relacionado à infância, fase em que os pequenos conseguem o que querem utilizando-se do choro como artifício, da mesma forma como agiriam os alunos presenciais. Esse pré-construído faz com que também sejam mobilizadas as noções de complacência e tolerância, corroborando a posição de sujeito do professor-paternalista do ensino presencial, aquele que avalia de forma arbitrária e, por vezes, sentimental, conferindo ao aluno o prolongamento de prazos para a conclusão das tarefas. Tais práticas iriam de encontro ao que ocorre na $\mathrm{EaD}$, em que a ação do aluno é bloqueada pelo sistema em caso de indisciplina quanto aos prazos. Esse novo paradigma na relação professor/aluno cria a reatualização de um discurso já cristalizado na sociedade, fazendo com que o cursista a distância construa uma faceta positiva de sua identidade.

Uma outra regularidade observada nas questões que se referiram às diferenças entre os participantes das duas modalidades foi a utilização dos verbos exigir e buscar ${ }^{3}$, por vezes acompanhados de intensificadores, e o emprego da locução correr atrás:

(04) S1- "Exatamente o mesmo, não, né, mas eu acho que em alguns aspectos o ensino a distância acaba exigindo mais, né, do aluno [...]"; S8-“A distância exige muito mais do aluno do que o presencial"; S2- "[...] Quando você tem que buscar pela Administração a distância, aí parte muito mais do aluno do que do professor em si, o aluno que tem que buscar cada vez mais ." S15- [...] O aluno a distância tem que correr atrás, você faz o curso, mais do que no presencial porque fica aquele negócio né... como você está ali no virtual e ficam muitas pessoas para o professor atender é... então, se você não correr atrás ...essa é a principal diferença. S16"Por ser a distância, você é que tem que se colocar na mente que "eu tenho que estudar, eu tenho que correr atrás"."

Além da carga semântica dos verbos em destaque que constroem a mudança de uma atitude passiva para a ação, a posição-sujeito assumida pelo enunciador o impele a empregar o intensificador para marcar posições dissonantes, ou seja, os sujeitos procuram representar o aluno a distância como um discente-pesquisador ávido por conhecimento, ao contrário do aluno presencial, que precisaria de menor esforço para aprender, já que o professor está disponível o tempo todo.

Esse imaginário de um aluno autônomo, participante da $\mathrm{EaD}$, é recente e constrói um deslocamento de sentido da figura pré-construída do aluno tradicional, conhecida antes do advento das Novas Tecnologias de Informação e Comunicação, para um novo estudante, o qual só conseguirá êxito se dedicar um esforço extra em relação

\footnotetext{
3 De acordo com o dicionário Houaiss (2004) tem-se, para exigir, entre outras, a acepção "impor determinação de; estabelecer; e para buscar, entre outras, a acepção de "esforçar-se por descobrir, encontrar; pesquisar, investigar".
} 
àquele que frequenta a sala de aula todos os dias. A construção desse discurso só é possível por filiar-se a um contexto social bem mais amplo no qual, como nos diz Minto (2009, p. 9), "a modalidade a distância incorpora-se ao modo de produção capitalista vigente, ou seja, de diversas formas o campo educacional se coloca a serviço do capital". Em outras palavras, interessa hoje ao mercado e à sociedade contemporânea capitalista que seus membros sejam capazes de lidar com maior rapidez e competência em suas áreas de atuação. Dessa forma, o sujeito, interpelado de forma não consciente pelo discurso econômico e pela tecnologia como produção sócio-histórica, representa o aluno $\mathrm{EaD}$ como aquele que corre atrás para se informar, formar-se e atender aos anseios do mercado que visa ao lucro.

Outra questão feita aos entrevistados diz respeito a sua opinião sobre o aluno a distância antes e depois de ingressarem em seus cursos on-line:

(05) S1-“Que elas queriam ter uma formação rápida e sem muito, como que eu posso dizer, sem muitas exigências"; S2- "Eu achava que era uma maneira mais fácil de conseguir um certificado."; S11- Então, eu achava que as pessoas queriam levar... eu achava que elas entravam porque era fácil".

As regularidades encontradas nas respostas mostram que a imagem inicial está sempre relacionada a uma possível facilidade na condução dos estudos e à rapidez na conclusão do curso proporcionadas pela modalidade. Esses sentidos são construídos sintática e semanticamente, com ou sem o uso do conectivo de causa (porque). Fica implícita, portanto, de modo parafrástico, a motivação inicial que os impeliu a ingressar na modalidade, ou seja, nota-se que os sujeitos quando ocupam a posição "aluno presencial" buscam a EaD por considerá-la inferior, em nível de exigências, ao ensino tradicional. O discurso é atravessado pela ideia pré-concebida que aquilo que se conhece, o que é tradicional, é sempre melhor. Assim, a ausência física de um professor, em sala de aula, que supervisiona, vigia e cobra constantemente possibilitaria ao sujeito levar o curso sem a necessidade de imprimir muito esforço.

Entretanto, essa visão é desconstruída quando saem de uma posição para ocupar a outra, tornando-se cursistas a distância. Enunciando dessa formação discursiva, colocam a supremacia do ensino presencial em xeque:

(06) S1- É...na verdade eu acho que é uma alternativa mais rápida sim, mas não é mais fácil.”; S8- [...] mas realmente é muito sério, porque você tem que se esforçar muito para alcançar seus objetivos, as médias, as notas, tudo [...]"; S12- "Depois eu vi que não é isso,é muito mais complicado que o presencial pelo fato que o aluno tem que estar disposto a isso, né, estar interessado."; S13- "Me surpreendeu porque é muito puxado, te dá uma base muito boa, me surpreendeu no nível de exigência.".

Agora, a locução conjuntiva de causa (pelo fato que) e a conjunção (porque) são utilizadas a fim de provocar um efeito de sentido inverso ao apontado no parágrafo anterior. Rompidos os preconceitos, os quais só eram possíveis de ser materializados na formação discursiva em que se encontravam, e por se perceberem na posição de sujeito aluno a distância, argumentam que a modalidade implica muito esforço. O emprego das conjunções adversativas reforça isso, bem como o uso do verbo surpreender, dialogando com a quebra dos julgamentos pré-concebidos sobre a modalidade.

Os sujeitos informantes que fizeram o curso quando já estavam mais velhos (acima dos 40 anos) representaram a EaD como a chance de suas vidas para concluir 
uma graduação, já que não puderam estudar antes por inúmeros motivos, principalmente pela falta de tempo. Questionados sobre as satisfações de terem feito parte da modalidade, elencam-se as regularidades:

(07) S1- "E a minha maior satisfação foi de ter conseguido um... finalmente, um diploma de curso de nível superior."; S8- "Ah, sim todos já aproveitando essa oportunidade, devido à idade muitos avós, uma faixa etária até de 62 anos de idade, de 30 e pouco a 62 , numa idade que você já não tem mais disposição para ficar quatro horas por dia em sala de aula."; S9- "Ah, faz, né, quem não tem tempo, que nem eu, porque numa presencial fica muito mais tempo, apesar de eu achar que a presencial é melhor, mas para as pessoas mais velhas, como é o meu caso, né, eu fiz acho que eu tinha 55,56 anos, pra gente assim, e que quer aprender, porque tem que ter determinação".

O sentido gerado nesses dizeres constrói uma representação da $\mathrm{EaD}$ como uma modalidade bastante democrática, inclusiva, que abre as portas do conhecimento para os mais maduros que não se sentem à vontade com as exigências do ensino presencial, mas que se sentem impelidos a aprender.Esse é um discurso que desconstrói a imagem social de que apenas os mais jovens podem concluir um curso superior ou mesmo uma pósgraduação. Dessa forma, a memória social que se tem do aluno universitário, recémsaído do ensino médio, sofre um deslocamento de sentido na sociedade atual. $\mathrm{O}$ advérbio de tempo finalmente, relacionado à locução pessoas mais velhas e ao vocábulo oportunidade, constrói um campo lexical que materializa essa possibilidade de interpretação.

Observando-se as regularidades lexicais utilizadas pelos sujeitos em seus dizeres, quando questionados se haveria algum pré-requisito para participar dessa modalidade, disseram:

(08) S7- "Na minha opinião é pra quem não tem muito tempo para frequentar uma sala de aula, quem tem facilidade em ser um autodidata [...]."; S8- "Ela tem que ter força de vontade, persistência."; S9- "Tem que ter força de vontade, né, determinação [...]"; S10- "Acho que a única característica é que a pessoa tem que estudar um pouquinho mais [...] porque você fica mais tempo estudando sozinho [...]"; S11- "Ah, ela tem que tem que ter objetivo, ela tem que estar focada no que ela quer, né, porque é muito fácil deixar de fazer as tarefas ali, tem que ser uma pessoa disciplinada no aspecto de estudo."; S12- Eu acho que precisa ter iniciativa, né [...]."; S13- "A pessoa tem que ter disciplina, é vontade de aprender, tem que ter uma postura de buscar o aprendizado."; S14- "Em relação ao conteúdo, você tinha que fazer praticamente sozinho, a gente até brincava e dizia "ai, é tão solitário, né"; S16- "Esforço, dedicação e estudo, né, como em qualquer outra universidade, particular, estadual, sem estudo não vai para frente.".

Das regularidades apresentadas, as representações depreendidas em nível lexical foram o autodidatismo, o esforço, a persistência, a solidão, a disciplina, o foco e a iniciativa. O posicionamento discursivo do aluno a distância em relação ao que significa ser um aluno a distância também ocorre por meio do léxico. De acordo com Pêcheux (2014, p. 146), “[...] o sentido de uma palavra, de uma expressão, de uma proposição não existe em 'si mesmo' [...], mas é determinado pelas posições ideológicas que estão em jogo no processo sócio-histórico [...]”. Para a construção da identidade desse aluno no contexto sócio-histórico contemporâneo, os enunciadores colocam em jogo uma relação conflituosa entre opostos, o aluno presencial e o aluno a distância, e constroem um sistema de representação materializando e atribuindo sentidos pelo léxico. Os vocábulos utilizados criam representações favoráveis acerca do aluno a distância, caracterizando-o como um sujeito aguerrido em relação aos estudos, que possui metas a 
serem alcançadas e que só poderá conseguir êxito com muita dedicação e autodidatismo.

\section{Considerações finais}

Retomando as questões de pesquisa que nortearam este trabalho, investigamos os dizeres daqueles que ocuparam, ou ocupam, a posição de aluno a distância, a fim de compreender a imagem construída a respeito da modalidade e do aluno dessa modalidade. Partimos da hipótese de que as representações desses sujeitos seriam positivas, refutando os estereótipos negativos que pairavam socialmente quando a educação a distância ainda se constituía como um modo de ensino-aprendizagem incipiente e o ensino presencial era visto como a única possibilidade válida pelo mercado de trabalho e pelas instituições educacionais.

Verificamos que o imaginário construído pelos sujeitos configura-se como positivo. O ensino a distância é visto como mais exigente em relação ao ensino presencial, o qual é representado como paternalista e facilitador da aprendizagem, criando um sujeito menos autônomo e mais dependente da figura do professor. Dessa forma, o aluno a distância é representado como um discente-pesquisador, condição fundamental para participar da modalidade e obter sucesso, seja em nível de graduação, pós-graduação ou em cursos de extensão.

Como conhecem as duas modalidades, quando seus discursos se deslocam da formação discursiva presencial para a formação discursiva a distância, desconstroem os aspectos ideológicos pré-concebidos de que a educação on-line é sinônimo de lassidão. Regularidades materializadas em nível lexical como o autodidatismo, o esforço, a persistência, a solidão, a disciplina, o foco e a iniciativa criam representações que nos remetem a um sujeito muito aplicado na realização de tarefas com prazos previamente estipulados.

Por fim, a educação a distância é representada pelos sujeitos mais velhos como uma chance para não se estagnar profissionalmente, oportunidade que lhes fora negada pela organização peculiar do ensino presencial ou pelas contingências do dia a dia. À existência desse oásis para o conhecimento, eles se sentem gratos pela oportunidade de inclusão social.

O sujeito é produzido no interior do discurso e sua identidade se constrói a partir das posições que ocupa, levando-se em conta as formações discursivas. Dependendo do lugar de onde enuncia e do momento sócio-histórico em que o faz, representa um dado objeto de forma diferente, dialogando com outras vozes que atravessam esse discurso para reafirmá-lo ou para romper com ele. As representações advindas dos dizeres sobre educação a distância, sempre em movimento, corroboram esse fluxo contínuo gerado pela historicidade e pela pluralidade do sujeito.

\section{REFERÊNCIAS}

ACHARD, P. et al. Papel da memória. 2. ed. Campinas: Pontes, 2007.

BELLONI, M. L. Educação a distância. 5. ed. Campinas: Autores associados, 2008. 
. Ensaio sobre a educação a distância no Brasil. Educação \& Sociedade, ano XXIII, n. 78, p. 117-142, abr./2002.

CHARAUDEAU, P. Discurso político. 2. ed. São Paulo: Contexto, 2013.

COURTINE, J.-J. Análise do discurso político: o discurso comunista endereçado aos cristãos. São Carlos: EdUfscar, 2009.

FERNANDES, C. A. Análise do discurso: reflexões introdutórias. 2. ed. São Carlos: Editora Claraluz, 2008.

FONTANA, H. A. Tecendo considerações acerca da educação a distância e seus paradigmas. In: FONTANA, H. A.; MACIEL, A. M. da R. (Orgs.). Educação a distância: por que ainda uma interrogação? Jundiaí: Paco Editorial, 2013. p. 11-26.

JODELET, D. Representações sociais: um domínio em expansão. In: . (Org.). As representações sociais. Rio de Janeiro: EdUERJ, 2001. p. 17-44.

MAINGUENEAU, D. Análise de textos de comunicação. São Paulo: Cortez, 2001.

MINTO, L. W. Educação superior e capitalismo no Brasil: problematizando o ensino a distância (EaD). Anais... VI Colóquio MARX-ENGELS. Campinas: Unicamp, 2009.

MOITA LOPES, L. P. da. Identidades fragmentadas: a construção discursiva de raça, gênero e sexualidade em sala de aula. Campinas: Mercado das Letras, 2002.

MOORE, M.; KEARSLEY, G. Educação a distância: uma visão integrada. São Paulo: Cenage Learning, 2007.

MORAN, J. O que é educação a distância. Universidade de São Paulo. 2002. Disponível em: <http://www.eca.usp.br/prof/moran.dist.htm>. Acesso em: 13 fev. 2015.

PÊCHEUX, M. O discurso: estrutura ou acontecimento. 6. ed. Campinas: Pontes Editores, 2012.

Semântica e discurso: uma crítica à afirmação do óbvio. 2. ed. Campinas: Editora da Unicamp, 1995.

PÊCHEUX, M.; FUCHS, C. A propósito da Análise Automática do Discurso: atualização e perspectivas (1975). In: GADET, F.; HAK, T. Por uma Análise automática do discurso: uma introdução à obra de Michel Pêcheux. Campinas: EdUnicamp, 1990.

PRETI, O. Educação a distância: inícios e indícios de um percurso. Cuiabá: UFMT, 1996.

ORLANDI, E. P. Identidade linguística escolar. In: SIGNORINI, I. (Org.). Língua(gem) e identidade. Campinas: Mercado das Letras, 1998.

WOODWARD, K. Identidade e diferença: uma introdução teórica e conceitual. In: SILVA, T. T. da. (Org.). Identidade e diferença: a perspectiva dos Estudos Culturais. 15. ed. Petrópolis: Vozes, 2014. p. 7-72.

Recebido em: 30/08/2017

Aprovado em: 06/11/2017 